\title{
THE INDIAN-FRENCH TRISHNA MISSION : EARTH OBSERVATION IN THE THERMAL INFRARED WITH HIGH SPATIO-TEMPORAL RESOLUTION
}

\author{
J.-P. Lagouarde ${ }^{1}$, B.K. Bhattacharya ${ }^{2}$, P. Crébassol ${ }^{3}$, P. Gamet ${ }^{3}$, S. S. Babu ${ }^{4}$, G. Boulet ${ }^{5}$, \\ X. Briottet ${ }^{6}$, K.M. Buddhiraju ${ }^{7}$, S. Cherchali ${ }^{3}$, I. Dadou $^{8}$, G. Dedieu ${ }^{9}$, M. Gouhier ${ }^{10}$, O. Hagolle ${ }^{9}$, \\ M. Irvine ${ }^{1}$, F. Jacob ${ }^{11}$, A. Kumar ${ }^{12}$, K. K. Kumar ${ }^{4}$, B. Laignel $^{13}$, K. Mallick ${ }^{14}$, C.S. Murthy ${ }^{15}$, \\ A. Olioso ${ }^{16}$, C. Ottlé ${ }^{17}$, M. R. Pandya ${ }^{2}$, P. V. Raju ${ }^{15}$, J.-L. Roujean ${ }^{9}$, M. Sekhar ${ }^{18}$, M.V. Shukla ${ }^{2}$, \\ S. K. Singh ${ }^{2}$, J. Sobrino ${ }^{19}$, R. Ramakrishnan ${ }^{2}$ \\ 1. INRA, UMR 1391 ISPA, F-33140 Villenave d'Ornon, France \\ 2. ISRO, Space Applications Centre, Ahmedabad 380015, India \\ 3. CNES, 18 av. Edouard Belin, F-31401 Toulouse, France \\ 4. ISRO, Space Physics Laboratory, Thiruvananthapuram 695 022, India \\ 5. IRD, UMR 5126 CESBIO, F-31401 Toulouse, France \\ 6. ONERA, DOTA, 2 av. Edouard Belin, F-31055 Toulouse, France \\ 7. ISRO, ITT(B), Space technology cell, IIT Bombay, Mumbai 400 076, India \\ 8. LEGOS, 18 av. Edouard Belin, F-31401 Toulouse, France \\ 9. CESBIO, Université de Toulouse, UMR 5126 CESBIO, F-31401 Toulouse, France \\ 10. OPGC, LMV, Université Clermont Auvergne, Clermont-Ferrand, France \\ 11. IRD, UMR 1221 LISAH, 2 place Viala, F-34060 Montpellier, France \\ 12. ISRO, IIRS, Indian Institute of Remote Sensing, Uttarakhand 248 001, India \\ 13. Université de Rouen, UMR 6143 M2C, F-76821 Mont Saint Aignan, France \\ ${ }^{14 .}$ LIST, ERIN, 41, rue du Brill, L-4422 Belvaux, Luxembourg \\ 15. ISRO, NRSC, National Remote Sensing Centre, Hyderabad 500 037, India \\ 16. INRA, UMR 1114 EMMAH, F-84000 Avignon, France \\ 17. LSCE, UMR 8212, Centre d'Etudes de Saclay, F-91191 Gif-sur-Yvette, France \\ 18. IISc, CV Raman Rd, Bengaluru, Karnataka 560 012, India \\ 19. Universitat de Valencia, UCG/IPL, Parque Científico, E-46980 Paterna, Spain
}

\begin{abstract}
The monitoring of the water cycle at the Earth surface which tightly interacts with the climate change processes as well as a number of practical applications (agriculture, soil and water quality assessment, irrigation and water resource management, etc...) requires surface temperature measurements at local scale. Such is the goal of the IndianFrench high spatio-temporal TRISHNA mission (Thermal

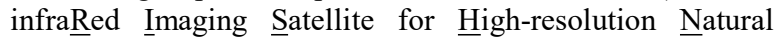
resource Assessment). The scientific objectives of the mission and research work conducted to consolidate the mission specifications are presented. Progress in modelling of surface fluxes is then discussed. The main specifications of the mission such as the revisit, the spatial resolution, the overpass time, the spectral bands and the orbit are analyzed and justified. The resulting baseline of the mission is given.
\end{abstract}

Index Terms - Thermal infrared, satellite, water stress, water management, climate change

\section{INTRODUCTION}

The interactions between climate change and the pressure exerted on environment by human activities (such as agriculture, urbanization, etc... [1]) directly impact surface water and energy budgets where the land and sea surface temperatures (LST and SST) appear as key signatures. The need of space borne systems combining both high spatial resolution and high revisit frequency in thermal infrared (TIR), which do not exist today, is now largely recognized by the scientific community and end-users. After several previous advanced studies (MISTIGRI [2], THIRSTY [3]), a project, TRISHNA, is currently in the feasibility 
assessment phase, conducted by the French Space Agency (CNES) and the Indian Space Research Organization (ISRO). It is presented below.

\section{SCIENTIFIC OBJECTIVES}

Together with the absorption of solar radiation, thermal emission is a fundamental process of the Earth system and of its energy budget. No surprisingly, the measurement of thermal emission can provide insights in a variety of Earth's compartments. THRISHNA addresses six objectives, two of which being used as the drivers of the mission design.

\subsection{Ecosystem stress and water use (design driver)}

LST is a key information to estimate evapotranspiration (ET), a crucial component of the water cycle. For agriculture which represents about $70 \%$ of the water consumption at global scale, applications to stress detection and irrigation optimization techniques are expected for a better management of water resources, improved crop production forecast and food security assessment. As $\mathrm{CO}_{2}$ and water transfers in plants are tightly coupled, and as water is the vector of many dissolved materials within the soil, LST can help to monitor biogeochemical cycles with applications to water quality and soil pollution monitoring. Dealing with hydrology, improved estimation of ET at watershed scale should also facilitate the closure of water budgets and estimation of infiltration, runoff, river flow, etc... Other application will be found in the field of ecology (e.g. mapping of microclimates, permafrost melting etc.).

\subsection{Coastal and inland waters (design driver)}

A better assessment of the sub-mesoscale activity in relation with coastal ecosystems productivity and of gas fluxes $\left(\mathrm{CO}_{2}\right.$, $\mathrm{CH}_{4}$ ) at the air-sea interfaces is expected from high spatiotemporal resolution SST. The availability of such SST data will open the way to a large number of applications: water quality, algae blooms, fish resource, fresh water resurgences, water discharges and storm surges (e.g. pollutants, thermal plumes etc.) among others. Moreover, the surface temperature of lakes has been defined as an essential climate variable by GCOS (Global Climate Observing System). The study of sea ice (extent, growth/decay of ice, feedback with climate) will also benefit from TRISHNA data.

\subsection{Urban microclimates monitoring}

More and more efforts are devoted to the characterization of urban heat islands (UHI) and to their possible mitigation or heat action plans for comfort of inhabitants (by 'greening' of the city, urban planning or control of air conditioning energy consumption for instance). Improved evaporation estimations should also provide better inputs for urban and peri-urban hydrology studies.

\subsection{Solid Earth}

TRISHNA should improve the detection of thermal anomalies with various applications: peat or coal fires mapping, geothermal exploration, possibly earthquakes precursors, among others. It could also contribute to the monitoring of volcanic activity through the early detection of lava hot spots.

\subsection{Cryosphere}

The feedbacks between climate and melting processes make the monitoring of snow and ice critical in polar regions. It is also particularly important for glaciers and glacial high altitude lakes in mountainous regions as the snow and glacier melt runoff represents a perennial source of water for river basins. This is crucial for India which is partly dependent on Himalayan cryosphere.

\subsection{Atmosphere}

Different information on atmosphere (precipitable water content) and clouds (type, height) can be derived from thermal infrared data for improving Earth radiative budgets.

\section{RECENT RESEARCH RESULTS}

\subsection{Impact of atmospheric turbulence on LST}

The atmospheric turbulence near the surface generates LST temporal fluctuations. It has been shown [4] that high frequency fluctuations which correspond to turbulent structures of a few meters typical scale propagating in the surface boundary layer under the influence of wind are smoothed out for decametric pixels $(50-100 \mathrm{~m})$. Low frequency structures within the planetary boundary layer, conversely, have typical scales of several hundred meters and can trigger significant fluctuations both in time and in amplitude on pixels of smaller size. It results in an uncertainty on instantaneous satellite LST measurements which has been characterized using both experimental data and Large Eddy Simulation (LES) simulation results.

\subsection{TIR directional anisotropy}

LST measurements are also prone to significant directional anisotropy effects (anisotropy is here defined as the difference between temperatures observed in oblique and nadir viewing angles). Experimental work based on airborne thermal imagery revealed significant hot spot effects over forest and urban canopies obtained when the surface is viewed exactly in the direction of the Sun (i.e. Sun, sensor, 
and surface aligned), the sunlit elements leading to an undesired spurious peak in temperature ([5]). Different modelling approaches have been proposed to simulate anisotropy ([5], [6], [7], [8]), but their complexity makes none of these approaches well suited to an operational processing of satellite data. For this purpose attempts are made to develop simpler parametric models ([9], [10]), but the assessment of TIR directional anisotropy still remains a concern for delivering robust operational products

\subsection{Surface fluxes modelling}

Different modelling approaches are developed for estimating ET. They are either based on solving the surface energy budget for one particular pixel independently from the others ('residual' or 'single pixel' methods), or on scaling ET directly from LST between min and max levels identified on the image ('contextual' methods). A review can be found in [11], and many examples of satellite-derived ET maps are provided in the literature ([12], [13], [14]). The EVASPA platform (EVapotranspiration Assessment from SPAce) brings several algorithms all together to provide an ensemble simulation with the uncertainty on final ET products [15]. To cope with the lack of LST data for cloudy days, research efforts are devoted to temporal gap-filling between discrete ET estimations. Significant progress is expected from alternative efficient supports, such as surface humidity or meteorological models outputs for instance, to replace evaporative fraction or stress index classically used up to now.

\section{JUSTIFICATION OF MISSION SPECIFICATIONS}

The highest possible revisit period would be desirable in order (i) to cope with the limitations of data availability due to clouds and (ii) to minimize the impact of uncertainty in LST due to atmospheric turbulence on the accuracy of final ET and water budget products. However, the requirement of global coverage severely constrains the swath angle for a single satellite mission. It results that only a 3 day-revisit can be achieved with a reasonable scan angle lower than $35^{\circ}$.

An analysis of the size of fields in a typical agricultural landscape in the South West of France led us to recommend a resolution close to $50 \mathrm{~m}$, corresponding to about a hundred meters at the swath edges. In many places of India, the very fragmented landscape makes $50 \mathrm{~m}$ at least mandatory [16]. However, at lower resolution, the atmospheric turbulence may induce a too significant uncertainty on LST (see section 3.1). Technical constraints are also to be considered. In particular the size of existing/under development detectors is still a technical limitation against the swath. The final trade-off is a $50 \mathrm{~m}$ spatial resolution at nadir.

Four reasons led us to recommend a $1 \mathrm{pm}$ overpass time. (1) According to models, it provides the best accuracy on ET retrievals [17]. (2) The lower sensitivity of time $(\mathrm{d}(\mathrm{LST}) / \mathrm{dt}$ close to $0{ }^{\circ} \mathrm{C} /$ hour at that moment) facilitates the combination with surface or meteorological models which have time steps of around half an hour. For comparison, around 10:00 (solar time), the variation of LST is about $4{ }^{\circ} \mathrm{C} /$ hour. (3) The corresponding night overpass around $1 \mathrm{am}$ is best adapted to measurements over water bodies because late enough to remove possible thermal inertia effects. (4) For mid latitudes, the directional anisotropy error on LST is reduced because the hot spot is situated in a plane perpendicular to the scan line [10].

A detailed analysis of the 3 day orbit at $666 \mathrm{~km}$ selected for THIRSTY [2] revealed it was not suited for the intertropical zone in which data may be affected by hot spot during several months per year [10]. As no robust model close to the hot spot peak is available today to correct LST data, an alternative orbit with a 8 day-revisit $(761 \mathrm{~km})$ was retained. Its $3 / 2 / 3$ sub-cycles could provide at least 2 hot spot free data out of 3 in the inter-tropical zone.

In the TIR, two bands centered on 10.3 and $11.5 \mu \mathrm{m}(\sim 1 \mu \mathrm{m}$ bandwidth) have been selected to apply the split-window method. Two bands centered at 8.6 and $9.1 \mu \mathrm{m}(\sim 0.35 \mu \mathrm{m}$ bandwidth) are added to perform the temperature emissivity separation using the TES method [18]. The exact shape of TIR spectral filters is currently being studied using an end-to-end simulator. Moreover, a study (not detailed here) has been conducted to demonstrate that it is mandatory to embark both TIR and VNIR/SWIR instruments on the same platform. In the VNIR domain, the vegetation bands at 0.650 and $0.860 \mu \mathrm{m}$ are mandatory. A blue band $(0.485 \mu \mathrm{m})$ with possibly a cirrus band $(1.38 \mu \mathrm{m})$ both acquired at lower resolution $(100-200 \mathrm{~m})$ are required for cloud discrimination. A green band $(0.555 \mu \mathrm{m})$ is devoted to coastal applications and snow discrimination. Finally a $1.650 \mu \mathrm{m}$ SWIR band is added to address aerosol characterization and albedo estimation particularly.

Because of the intrinsic atmospheric turbulence induced uncertainty on LST, a NeDT of $0.3 \mathrm{~K} @ 300 \mathrm{~K}$ is sufficient for continental surfaces.

\section{CONCLUSION}

The summary of the baseline is as follows:

- Resolution: $50 \mathrm{~m}$ at nadir ( $<100 \mathrm{~m}$ edges of swath). Binned at $1000 \mathrm{~m}$ over oceans.

- Revisit and coverage: 3 observations for any ground location per 8 days period (from the 3 subcycles of a 8 day-orbit at $761 \mathrm{~km}$ ), global coverage.

- NeDT: $0.3 \mathrm{~K}(0.1 \mathrm{~K}$ for ocean binned at $1 \mathrm{~km})$ 
Spectral bands

- $\quad$ TIR: $8.6 \mu \mathrm{m}, 9.1 \mu \mathrm{m}, 10.3 \mu \mathrm{m}$ and $11.5 \mu \mathrm{m}$

- VNIR: 0.485, 0.555, 0.650 and $0.860 \mu \mathrm{m}$

- SWIR: $1.650 \mu \mathrm{m} .1 .38 \mu \mathrm{m}$ highly desirable.

- Possible degradation of the spatial resolution for blue $(0.485 \mu \mathrm{m})$ and cirrus $(1.38 \mu \mathrm{m})$ bands.

Two preliminary studies of TIR instrumental concepts based on a classical scanner and a step and stare design are currently being conducted.

TRISHNA is currently in A phase (feasibilty assessment) till end 2019. It will be followed by a one-year B phase. The launch could be foreseen at 2024-2025 horizon. TRISHNA remains very original in the international context of the high spatio-temporal TIR with only the ECOSTRESS project aboard the ISS (https://ecostress.jpl.nasa.gov/), HyspIRI (https://hyspiri.jpl.nasa.gov/) in the USA, and a similar study starting at ESA in Europe (LSTM, same proceedings).

Acknowledgements. This work is supported by the 'Centre National d'Etudes Spatiales' (CNES) through the TOSCA group (Terre, Océan, Surfaces Continentales, Atmosphère). The authors are thankful to S. S. Sarkar, Co-chair of TRISHNA project team, Director, Space Applications Centre and Chairman, Indian Space Research Organization for encouraging to define this science mission.

\section{REFERENCES}

[1] IPCC, 2014. Fifth Assessment Report (AR5). http://www.ipcc.ch/report/ar5/index.shtml

[2] J.-P. Lagouarde, M. Bach, J.A. Sobrino, G. Boulet, X. Briottet, S. Cherchali, B. Coudert, I. Dadou, G. Dedieu, P. Gamet, O. Hagolle, F. Jacob, F. Nerry, A. Olioso, C. Ottlé, J.-L. Roujean, and G. Fargant, 2013. The MISTIGRI Thermal Infrared project: scientific objectives and mission specifications. Int. J. Remote Sens., 34 (9-10), 3437-3466.

[3] P. Crebassol, J.-P. Lagouarde, and S. Hook, 2014. THIRSTY Thermal InfraRed SpaTial System. IEEE Geos. Rem. Sens. Symp., 3021-3024. http://dx.doi.org/10.1109/IGARSS.2014.6947113.

[4] J.-P. Lagouarde, M. Irvine, and S. Dupont, 2016. Atmospheric turbulence induced errors on measurements of surface temperature from space. Remote Sens. Environ., 168, 40-53.

[5] J-P. Lagouarde, A. Henon, B. Kurz, P. Moreau, M. Irvine, J. Voogt, and P. Mestayer. 2010. Modelling daytime thermal infrared directional anisotropy over Toulouse city centre. Remote Sens. Environ. 114, 87-105.

[6] D. Luquet, A. Vidal, J. Dauzat, A. Bégué, A. Olioso, and P. Clouvel, 2004. Using directional TIR measurements and 3D simulations to assess the limitations and opportunities of water stress indices. Remote Sens. Environ., 90, 53-62.

[7] W. Verhoef, L. Jia, Q. Xiao, and Z. Su, 2007. Unified OpticalThermal Four-Stream Radiative Transfer Theory for Homogeneous
Vegetation Canopies. IEEE Trans. Geos. and Remote Sens., Vol. 45 , No. 6, 1808-1822.

[8] C. Duffour, A. Olioso, J. Demarty, C. Van der Tol, and J.-P. Lagouarde, 2015. An evaluation of SCOPE: a tool to simulate the directional anisotropy of satellite-measured surface temperatures. Rem. Sens. Environ., 158, 362-375.

[9] K.Y. Vinnikov, Y. Yu, M.D. Goldberg, D. Tarpley, P. Romanov, I. Laszlo, and M. Chen, 2012. Angular anisotropy of satellite observations of land surface temperature. Geophys. Res. Lett. 39, L23802. http://dx.doi.org/10.1029/2012GL054059.

[10] C. Duffour, J.-P. Lagouarde., and J.-L. Roujean, 2016. A two parameter model to simulate thermal infrared directional effects for remote sensing applications. Rem. Sens. Environ. 186 250-261.

[11] J.-P. Lagouarde and G. Boulet, 2016. Energy Balance of Continental Surfaces and the Use of Surface Temperature, Chapter 10, 323 - 362. In: Land Surface Remote Sensing in Continental Hydrology, N. Baghdadi and M. Zribi Ed., ISTE Editions, ISBN : 9781785481048

[12] K. Mallick, B.K. Bhattacharya, V.U.M. Rao, D.R. Reddy, S. Banerjee, H. Venkatesh, V. Pandey, G. Kar, J. Mukherjee, S.P. Vyas, A.S. Gadgil, and N.K. Patel, 2009. Latent heat flux estimation in clear sky days over Indian agroecosystems using noontime satellite remote sensing data. Agric. For. Meteorol. 149 $1646-1665$.

[13] B.K. Bhattacharya, K. Mallick, N.K. Patel and J.S. Parihar, 2010. Regional clear sky evapotranspiration over agricultural land using remote sensing data from Indian geostationary meteorological satellite, J. Hydrol., 387, 65-80.

[14] M.C. Anderson, R.G. Allen, A. Morse, and W.P. Kustas, 2012. Use of Landsat thermal imagery in monitoring evapotranspiration and managing water resources Rem. Sens. Environ. 122 (2012) 5065.

[15] B. Gallego-Elvira, A. Olioso, M. Mira, S. Reyes-Castillo, G. Boulet, O. Marloie, S. Garrigues, D. Courault, M. Weiss, P. Chauvelon, and O. Boutron, 2013. EVASPA (EVapotranspiration Assessment from SPAce) tool: An overview. Procedia Environmental Sciences, 19, 303-310.

[16] R. Eswar, M. Sekhar, and B.K. Bhattacharya, 2013. A simple model for spatial disaggregation of evaporative fraction: comparative study with thermal sharpened land surface temperature data over India. J. of Geophys. Research: Atmospheres, 118 (21): $12,029-12,044$.

[17] E. Delogu, G. Boulet, A. Olioso, B. Coudert, J. Chirouze, E. Ceschia, V. Le Dantec, O. Marloie, G. Chehbouni, and J.-P. Lagouarde, 2012. Reconstruction of temporal variations of evapotranspiration using instantaneous estimates at the time of satellite overpass. Hydrology and Earth System Sciences, 16, 2995-3010. doi:10.5194/hess-16-2995-2012

[18] F. Jacob, A. Lesaignoux, A. Olioso, M. Weiss, K. Caillault, S. Jacquemoud, F. Nerry, A. French, T. Schmugge, X. Briottet, J.-P. Lagouarde, 2017. Reassessment of the temperature - emissivity separation from multispectral thermal infrared data: Introducing the impact of vegetation canopy by simulating the cavity effect with the SAIL-Thermique model. Remote Sens. of Environ., 198: 160-172. 